\title{
Atropine-Induced Bigeminy by Treating Bradycardia-Dependent Ectopy
}

\section{Ramón Eizaga Rebollar*, María Victoria García Palacios, Javier Morales Guerrero and Luis Miguel Torres Morera}

Department of Anesthesiology and Reanimation, Puerta del Mar University Hospital, Spain

\begin{abstract}
We report the case of a 9-year-old healthy boy who underwent day-surgery herniotomy under combined general and regional anesthesia. After inhalational induction, borderline bradycardia with Premature Ventricular Contractions (PVCs) was observed in ECG tracing, which worsened despite the adequate anesthetic management to avoid and treat arrhythmogenic triggers. Subsequent diagnostic tests were performed to rule out an underlying heart disease. Thereby, we conduct a brief review of ventricular ectopy in children with structurally normal hearts, both in the clinical and perioperative setting; and finally linked to our case in order to find out the cause of the abnormal electrical activity.
\end{abstract}

Keywords: Pediatrics; Anesthesia; Ectopy; Premature ventricular contractions; Bigeminy; Atropine

\section{Introduction}

Ventricular ectopy consists in extra impulses originating from an area distal to His-Purkinje system. It's classified as simple (PVCs) or complex (polimorphic PVCs, bigeminy, couplets, non-sustained tachycardia). PVCs are the most common ventricular arrhythmia in pediatric population, varying the prevalence with age in healthy children: $15-20 \%$ of neonates/infants, $10 \%$ of children and $20-$ $30 \%$ of adolescents. Ventricular ectopy can be related to cardiac causes like heart diseases (structural or functional abnormalities) or cardiac surgery; and non-cardiac causes like electrolyte disorders (hypokaliemia, hypomagnesemia, hypercalcemia), $\mathrm{pH}$ alterations (acidosis, alkalosis), drugs (antidepresants, adrenergics, anesthetics) or stress response (surgery, infection). PVCs may worsen the prognosis of children with cardiac pathology while they are generally considered benign in children with a structurally normal heart [1-4].

\section{Case Description}

A 9-year-old boy, weighing $60 \mathrm{~kg}$ and classified as ASA-I (American Society of Anesthesiologists physical status classification system), underwent day-surgery inguinal hernia repair under combined general and regional anesthesia. Patient was premedicated with oral midazolam $10 \mathrm{mg}$. After inhalational induction with sevoflurane $8 \%$, isolated PVCs were detected in ECG, with normal respiratory parameters $\left(\mathrm{SatO}_{2}\right.$ $99 \%$ and $\mathrm{EtCO}_{2} 35 \mathrm{mmHg}$ ), hemodynamic values in lower limit of normal (FC $70 \mathrm{bpm}$ and BP 90/60 $\mathrm{mmHg}$ ) and without abnormal heart sounds or murmurs. Hence we decided to continue the procedure, decreasing sevoflurane concentration to $2.5 \%\left(\mathrm{FiO}_{2} 0.4\right)$ for anesthetic maintenance and administering atropine $(0.6 \mathrm{mg})$ to treat borderline sinus bradycardia, both of which-sevoflurane and bradycardia-could induce PVCs. As heart rate increased (FC 90-100 bpm), PVCs became more frequent and finally assumed a bigeminal pattern (Figure 1). Fentanyl $(75 \mu \mathrm{g})$ was injected prior to supraglottic airway device placement and ilioinguinal/iliohypogastric block subsequently was performed for analgesia (levobupivacaine $0.25 \% 12 \mathrm{ml}$ ). Ventricular bigeminy persisted throughout the $40 \mathrm{~min}$ procedure, with no changes in monitored parameters and no complications during anesthesia emergence. In post-anesthesia care unit, a 12-lead ECG (Figure 2) and an echocardiogram were performed.

ECG: Isolated PVCs with left bundle branch block, normal QT and Tp-Te intervals.
Echocardiogram: No structural or functional abnormalities. After $2 \mathrm{~h}$ of uneventful stay, the patient was moved to the ward and, $12 \mathrm{~h}$ later, was finally discharged pending a Holter monitoring and a stress test, which finally were not carried out because of patient's decision.

\section{Discussion}

Ventricular ectopy in children can be a marker for serious cardiac pathology. It may be associated with structural heart disease, cardiomyopathy and long QT syndrome, all of which increase the risk of Ventricular Tachycardia (VT) and sudden death and demand follow-up echocardiogram, Holter monitoring and exercise stress test. In healthy children we must differentiate: 1) PVCs disappearing with exercise and/or originating from the left ventricle (right bundle branch block morphology), which generally subside during childhood, needing no follow-up. 2) PVCs not disappearing with exercise and/ or originating from the right ventricle (left bundle branch block morphology), which don't usually subside, requiring monitoring as they could be the first sign of an arrhythmogenic right ventricular cardiomyopathy. In structurally normal hearts, a higher burden of ectopy ( $24 \mathrm{~h}-\mathrm{PVC} \%$ ) has been correlated to a higher risk of left ventricle dilation or systolic dysfunction [1-8].

Perioperative ventricular ectopy in healthy children is relatively rare. It can be secondary to adrenergic stimulation (anxiety, pain, superficial anaesthesia), hypoxemia, hypercarbia, acidosis, hypotension, hypothermia, electrolyte disturbance or myocardial ischemia. It's noteworthy that certain anaesthetics and other perioperative medications (Table 1) can induce a long QT syndrome and potentially lead to ventricular ectopy and tachycardia-torsade de pointes-, especially in patients with congenital or acquired long QT syndrome. Long QT is not by itself a risk factor of torsade de pointes, being the electrophysiological substrate of this arrhythmia an increased transmural dispersion of repolarization, measured in ECG as

*Corresponding author: Ramón Eizaga Rebollar, Puerta del Mar University Hospital, Ana de Viya 21, Cádiz 11009, Spain, Tel: 0034-678256515; Fax: 0034956002984; E-mail: ramonchueizaga@hotmail.com

Received July 30, 2016; Accepted August 11, 2016; Published August 15, 2016

Citation: Rebollar RE, Palacios MVG, Guerrero JM, Morera LMT (2016) AtropineInduced Bigeminy by Treating Bradycardia-Dependent Ectopy. Cardiovasc Pharm Open Access 5: 193. doi: 10.4172/2329-6607.1000193

Copyright: (C) 2016 Rebollar RE, et al. This is an open-access article distributed under the terms of the Creative Commons Attribution License, which permits unrestricted use, distribution, and reproduction in any medium, provided the original author and source are credited. 
Citation: Rebollar RE, Palacios MVG, Guerrero JM, Morera LMT (2016) Atropine-Induced Bigeminy by Treating Bradycardia-Dependent Ectopy. Cardiovasc Pharm Open Access 5: 193. doi: 10.4172/2329-6607.1000193

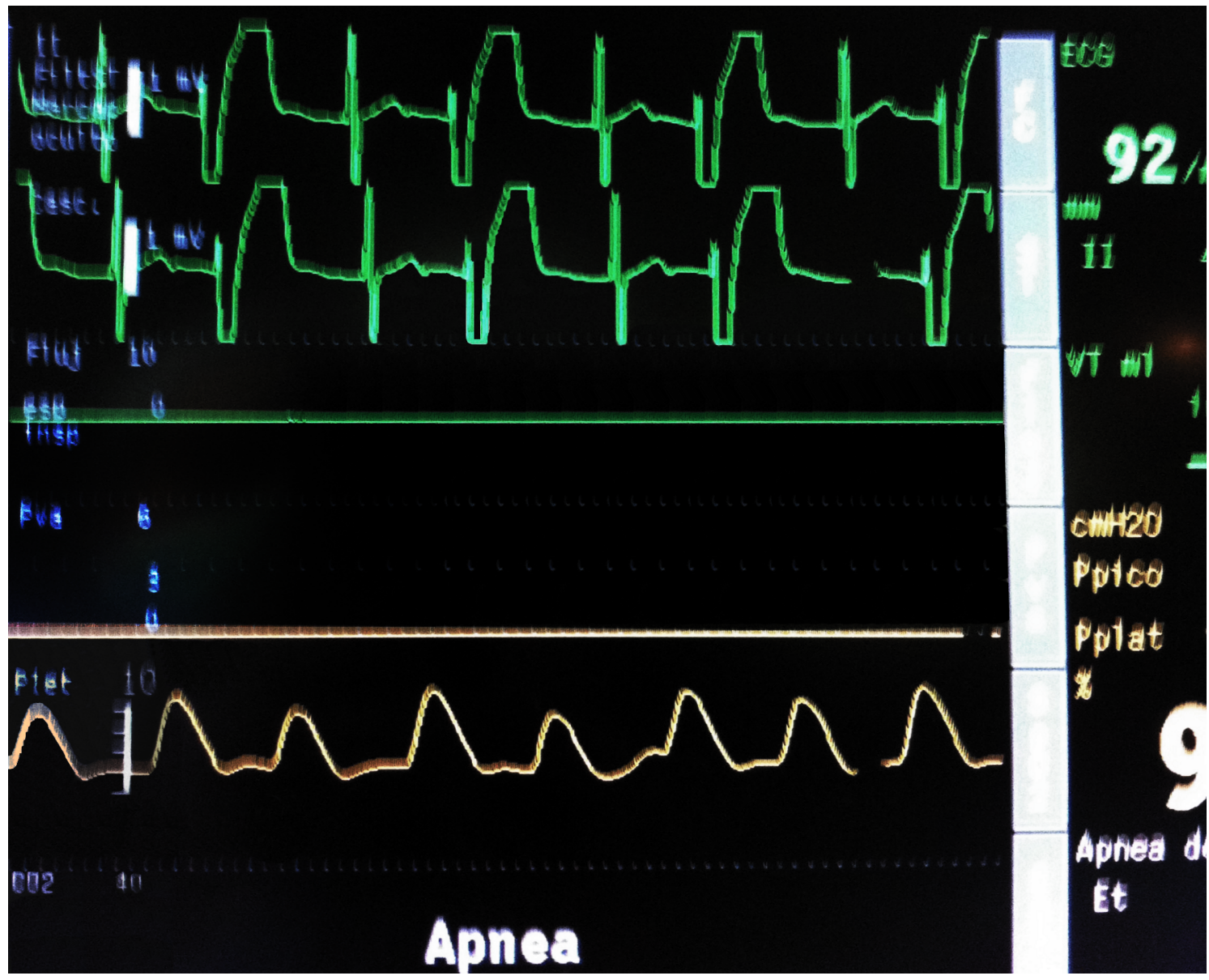

Figure 1: Ventricular bigeminy in multiparameter monitor.

\section{Perioperative drugs affecting QT interval prolongation}

$\checkmark$ Anesthetics: Halogenated agents, Thiopental

$\checkmark$ Opiods: Sufentanil, Methadone

$\checkmark$ NSAIDs: Ketorolac

$\checkmark$ Neuromuscular blockers: Succinylcoline

$\checkmark$ Anticholinesterases: Neostigmine

$\checkmark$ Anticholinergics: Atropine, Glycopyrrolate

$\checkmark$ Adrenergics: Epinephrine, Ephedrine

$\checkmark$ Antiemetics: Ondansetron, Droperidol

Antibiotics: Piperacilin/Tazobactam, Ampicilin/Sulbactam, Cefoxitine

Table 1: Perioperative drugs affecting QT interval prolongation.

a prolonged interval between the peak and the end of $\mathrm{T}$ wave (Tp-Te). Among the medication listed in Table 1, sevoflurane and ondansetron are remarkable (given its widespread use in pediatric anesthesia) because both drugs prolong QT interval but not Tp-Te interval, not increasing the risk of torsade de pointes in healthy children [9-15].

Anesthetic management of ventricular ectopy in healthy children must be based on exhaustive vigilance and hemodynamic monitoring, particularly during periods of enhanced sympathetic activity (induction and especially emergence); adequate anesthesia and analgesia; and maintenance of normoxemia, normocarbia, normothermia and normovolemia. It's best to avoid bradycardia as well as agents that decrease heart rate and prolong QT interval, as all of them could trigger ventricular ectopy or VT; likewise, caution should be taken when combining drugs influencing repolarization. Sevoflurane, nitrous oxide and propofol are considered good options as anesthetic agents, given their low arrhythmogenicity and side effect profile. Atropine should be contemplated for bradycardia-dependent ventricular ectopy. However, prophylactic antiarrhythmics are not recommended in these patients [15-19].

With regard to our case, in the patient's medical history we found he suffered from obesity (BMI $>95^{\text {th }}$ percentile), being classified as ASA-I when perhaps should have been scored as ASA-II. Obesity may be associated to increased heart rate, hypertension and left ventricular hypertrophy, all of which may lead to ventricular ectopy and tachycardia $[20,21]$; however, postoperative echocardiogram revealed normal left ventricular dimension or wall thickness. We also found that the child lost his mother-due to cancer-few months before the surgery. Emotional distress can be associated to sympathetic/parasympathetic imbalance, coronary arterial vasoconstriction or even increased QT dispersion, all of which may predispose to arrhythmia [22,23]. Perioperative adrenergic stimulation, causing potential ectopic activity, was offset with midazolam premedication for anxiety; sevoflurane induction to reach an optimal anesthetic level; and ilioinguinal/ iliohypogastric block for analgesia. Ventricular ectopy related to perioperative medication could have been provoked by sevoflurane induction, so it was promptly decreased to lower concentrations for anesthetic maintenance, with no ECG changes. And also by atropine, which was administered to treat a borderline sinus bradycardia that could have lead to ventricular ectopy, with no positive outcome or even worsening in ECG tracing, since the pattern turned into a bigeminal rhythm. 
Citation: Rebollar RE, Palacios MVG, Guerrero JM, Morera LMT (2016) Atropine-Induced Bigeminy by Treating Bradycardia-Dependent Ectopy. Cardiovasc Pharm Open Access 5: 193. doi: 10.4172/2329-6607.1000193

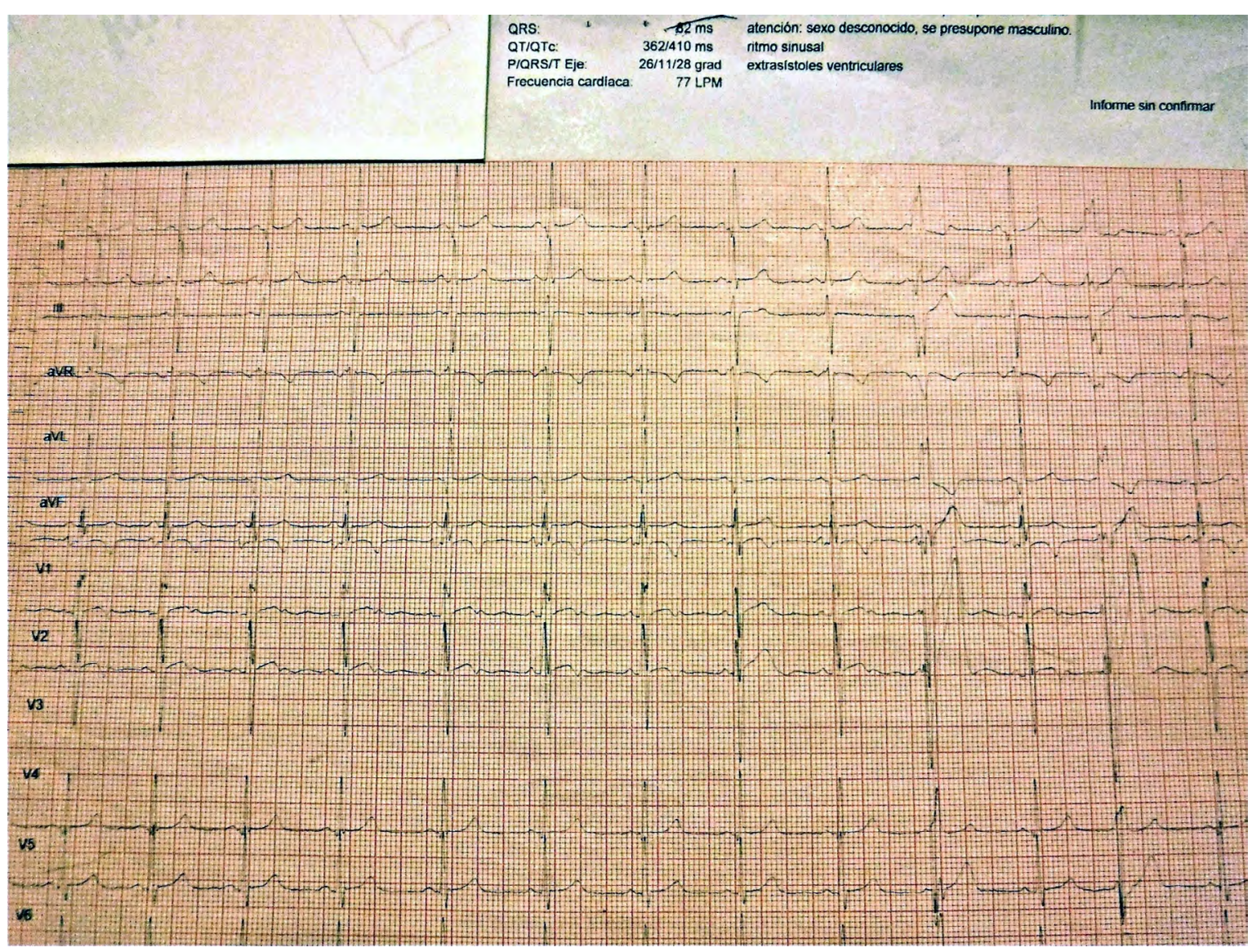

Figure 2: Isolated PVCs with left bundle branch block in 12-lead ECG.

In conclusion, we consider that the reported event turned out to be an atropine-induced ventricular bigeminy by treating bradycardiadependent ectopy, in a child with a structurally normal heart and a background of emotional distress. This case highlights the importance of anesthetic management of perioperative ventricular ectopy in children, summarizing two main key points:

- Exhaustive vigilance and monitoring, especially during induction and emergence.

- Avoid arrhythmogenic triggers, with particular caution on perioperative medication.

\section{References}

1. West L, Beerman L, Arora G (2015) Ventricular ectopy in children without known heart disease. J Pediatr 166: 338-342.

2. Crosson JE, Callans DJ, Bradley DJ, Dubin A, Epstein M, et al. (2014) PACES/ HRS expert consensus statement on the evaluation and management of ventricular arrhythmias in the child with structurally normal heart. Heart Rhythm 11: e55-78.

3. Kakavand B, Ballard $\mathrm{HO}$ (2010) Frequent ventricular premature beats in children with structurally normal heart: a cause for reversible left ventricular dysfunction? Pediatr Cardiol 31: 986-990.

4. Das BB, Sharma J (2004) Repolarization abnormalities in children with a structurally normal heart and ventricular ectopy. Pediatr Cardiol 25: 354-366.

5. Cagdas D, Celiker A, Ozer S (2008) Premature ventricular contractions in normal children. Turk J Pediatr 50: 260-264.

6. Abadir S, Blanchet CG, Dahdah N, Mawad W, Khairy P, et al. (2014) Premature ventricular contractions in healthy children: does the burden of ectopy matter? Can J Cardiol 30: S110.
7. Spector ZZ, Seslar SP (2016) Premature ventricular contraction-induced cardiomyopathy in children. Cardiol Young 17: 1-7.

8. Beaufort-Krol GC, Dijkstra SS, Bink-Boelkens MT (2008) Natural history of ventricular premature contractions in children with a structurally normal heart: does origin matter? Europace 10: 998-1003

9. Nagele P, Pal S, Brown F, Blood J, Miller JP, et al. (2012) Postoperative QT interval prolongation in patients undergoing noncardiac surgery under general anesthesia. Anesthesiology 117: 321-328.

10. Fazio G, Vernuccio F, Grutta G, Lo Re GL (2013) Drugs to be avoided in patients with long QT syndrome: Focus on the anaesthesiological management. World J Cardiol 5: 87-93.

11. Whyte SD, Nathan A, Myers D, Watkins SC, Kannankeril PJ, et al. (2014) The safety of modern anesthesia for children with long QT syndrome. Anesth Analg 119: 932-938.

12. Aypar E, Karagoz AH, Ozer S, Celiker A, Ocal T (2007) The effects of sevoflurane and desflurane anesthesia on QTc interval and cardiac rhythm in children. Paediatr Anaesth 17: 563-567.

13. Whyte SD, Booker PD, Buckley DG (2005) The effects of propofol and sevoflurane on the QT interval and transmural dispersion of repolarization in children. Anesth Analg 100: 71-77.

14. Mehta D, Sanatani S, Whyte SD (2010) The effects of droperidol and ondansetron on dispersion of myocardial repolarization in children. Paediatr Anaesth 20: 905-912.

15. Staikou C, Stamelos M, Stavroulakis E (2014) Impact of anaesthetic drugs and adjuvants on ECG markers of torsadogenicity. Br J Anaesth 112: 217-230.

16. Shortt R, Ashbury T, Milne B (2005) Anesthetic management of a patient with asymptomatic ventricular tachycardia. Paediatr Anaesth 15: 782-785.

17. Waxman BN (2015) A 13-year-old girl trigeminy during anesthesia for outpatient dental surgery: a case report. Anesth Prog 62: 110-113. 
Citation: Rebollar RE, Palacios MVG, Guerrero JM, Morera LMT (2016) Atropine-Induced Bigeminy by Treating Bradycardia-Dependent Ectopy. Cardiovasc Pharm Open Access 5: 193. doi: 10.4172/2329-6607.1000193

18. Nathan AT, Berkowitz DH, Montenegro LM, Nicolson SC, Vetter VL, et al. (2011) Implications of anesthesia in children with long QT syndrome. Anesth Analg 112: 1163-1168

19. Mizuno J, Kato S, Ino K, Yoshimura T, Yunokawa S, et al. (2009) Intermittent bradycardia-dependent bundle branch block during sevoflurane and remifentanil anesthesia. Masui 58: 976-979.

20. Nafiu OO, Reynolds PI, Bamgbadge OA, Tremper KK, Welch K, et al. (2007) Childhood body mass index and perioperative complications. Paediatr Anaesth 17: $426-430$
21. Uner A, Dogan M, Epcacan Z, Epcacan S (2014) The effect of childhood obesity in cardiac funcions. J Pediatr Endocrinol Metabol 27: 261-271.

22. Taggart $P$, Boyett MR, Logantha S, Lambiase PD (2011) Anger, emotion, and arrhythmias: from brain to heart. Front Physiol 2: 67.

23. Kelmanson IA (2014) High anxiety in clinically healthy patients and increased QT dispersion: a meta-analysis. Eur J Prev Cardiol 21: 1568-1574. 